\title{
Feeding Preferences of Acanthaster planci (Echinodermata: Asteroidea) under Controlled Conditions of Food Availability ${ }^{1}$
}

\author{
Morgan S. Pratchett ${ }^{2}$
}

\begin{abstract}
Feeding preferences of the crown-of-thorns sea star, Acanthaster planci (L.), were studied in a series of laboratory-based feeding trials wherein sea stars were provided with equal availability of six different coral species. The order in which corals were consumed was then used to ascertain feeding preferences. Crown-of-thorns sea stars exhibited strong and consistent feeding preferences across replicate feeding trials. The most readily eaten coral species was Acropora byacinthus, followed by A. gemmifera, A. nasuta, A. formosa, Stylophora pistillata, Montipora undata, and Pocillopora damicornis. Crown-of-thorns sea stars also consumed Goniopora lobata, Fungia fungites, Goniastrea retiformes, and Pavona cactus but only after all Acropora and Montipora (Family Acroporidae) as well as Pocillopora and Stylophora (Family Pocilloporidae) were eaten. The leastpreferred corals were Favites abidita, Porites lobata, Symphyllia recta, Echinopora borrida, and Porites cylindrica. Of these, P. cylindrica was never eaten in any of the feeding trials in which it was offered. Observed feeding preferences substantiate findings from previous studies, where corals from the families Acroporidae and Pocilloporidae were preferred over all other corals. Further research is required to assess the underlying basis of feeding preferences of $A$. planci, but this study confirms that these starfish readily distinguish between different corals and have innate preferences for certain species. Still, most corals were eventually consumed, showing that when food is limited (during population outbreaks) $A$. planci is likely to consume virtually all different coral species, causing extreme devastation to coral reef ecosystems.
\end{abstract}

The coral-feeding crown-of-thorns sea star, Acanthaster planci (L.), is renowned for its capacity to cause large-scale devastation on tropical coral reefs. Mostly, A. planci occurs at very low densities (typically $<1$ starfish $\mathrm{ha}^{-1}$ ) and has limited effect on coral reef ecosystems (Dana et al. 1972, Glynn 1973). However, at very high densities, during outbreaks, $A$. planci can kill up to $80 \%$ of corals

\footnotetext{
${ }^{1}$ This research was funded by the Great Barrier Reef Marine Park Authority. Manuscript accepted 13 April 2006.

${ }^{2}$ ARC Centre of Excellence for Coral Reef Studies, James Cook University, Townsville, Q4811, Australia (phone: 6174781 5747; fax: 6174725 1570; e-mail: morgan.pratchett@jcu.edu.au).
}

Pacific Science (2007), vol. 61, no. 1:113-120

(C) 2007 by University of Hawai'i Press

All rights reserved across large reef areas (Chesher 1969, Pearson and Endean 1969). Even at moderate densities $A$. planci has the potential to greatly modify coral community structure by selectively feeding on different coral species. In the eastern Pacific, for example, Glynn (1976) found that $A$. planci reduces coral diversity and increases dominance of Pocillopora damicornis by selectively feeding on rare coral species, such as Pavona varians (see also Branham et al. 1971, Glynn 1987, Chess et al. 1997). In contrast, in the western and central Pacific and in the Indian Ocean, $A$. planci tends to prefer corals of the genus Acropora, which are highly abundant and often dominate coral communities in those regions (Potts 1981, Moran 1986, Birkeland and Lucas 1990). By feeding selectively on highly abundant corals, A. planci may facilitate growth and recruitment of other less-common coral species and effectively increase coral diversity (Porter 1972). 
Acanthaster planci sea stars are clearly very selective in their choice of prey (Glynn 1974, 1987, Ormond et al. 1976, De'ath and Moran 1998, Pratchett 2001), and their feeding preferences are fundamental in determining their effects on coral communities. Despite this, feeding preferences of $A$. planci, as well as the factors that influence these preferences, remain poorly understood. The choice of diets for all animals is widely assumed to follow principles of optimal foraging theory, whereby foraging activities adopted by animals are those that maximize the net rate of energy intake (Ormond et al. 1976, Hughes 1980). However, there are many other factors, such as the distribution and abundance of prey types as well as interspecific competition, that can constrain the range of prey types an animal may consume (e.g., Berumen et al. 2005). Consequently, it can be very difficult to establish which factors influence feeding preferences, even for the most highly selective feeders (Hughes 1980). For A. planci, many factors have been proposed to influence feeding preferences, including the nutritional content of corals, coral growth form, coral defenses (e.g., mesenterial filaments, nematocysts, and secondary metabolites), host defense by crustacean symbionts, the distribution and abundance of corals, and prior conditioning and learned behavior of the sea stars (reviewed by Moran 1986, Birkeland and Lucas 1990).

In the field, $A$. planci tends to exhibit a well-defined hierarchy of feeding preferences, with Acropora being the most preferred genus of corals and Porites the least preferred (Keesing 1990, 1992, De'ath and Moran 1998). These strong and consistent feeding preferences are partly attributable to variation in the energy and protein content among different corals (Keesing 1990). Keesing (1990) also showed that $A$. planci feeds much more efficiently on Acropora spp., compared with Porites spp. However, observed feeding preferences of $A$. planci are not consistent with differences in nutritional content or handling times for other coral genera (Keesing 1990). As a consequence, various constraints have been put forward to account for departures from optimal foraging theory and explain why $A$. planci does not consistently select the most nutritious prey corals. Potts (1981) suggested that coral prey that are readily consumed by $A$. planci are species that are least avoided, rather than those that are most preferred. Defensive mechanisms of scleractinian corals, including nematocysts, mesenterial filaments, secondary metabolites, and the antagonistic behavior of crustacean guards, may all deter starfish from feeding on certain corals (Potts 1981). In the bestdocumented example, Glynn (1974, 1976, 1987) and Pratchett (2001) showed that crustacean guards within some coral species attack $A$. planci and deter them from feeding on their host corals. Still, both Pocillopora and Stylophora, which contain highly antagonistic crustacean guards, are among the most highly preferred coral prey of $A$. planci on the Great Barrier Reef (e.g., Keesing 1990, De'ath and Moran 1998), suggesting that these crustacean guards have only limited influence on the overall feeding preferences of the sea stars. The specific role and relative importance of different factors in determining feeding preferences of $A$. planci have not been tested. Also, much of the current information about feeding preferences of $A$. planci is qualitative, rather than quantitative (reviewed by Potts 1981, Moran 1986). Further, most field-based studies infer feeding preferences from measures of dietary electivity, which are highly confounded by differences in the size, abundance, and accessibility of different corals (De'ath and Moran 1998).

The purpose of this study was to examine feeding preferences of $A$. planci under laboratory conditions, providing the sea stars with equal availability of alternate prey corals in aquariums. Such studies are essential to test whether $A$. planci has definitive feeding preferences independent of variation in the size or abundance of different coral species, as suggested by Moran (1986). Previous studies that have explored feeding preferences of $A$. planci in the laboratory (Brauer et al. 1970, Ormond et al. 1976, Keesing 1990, Sonoda and Paul 1993) have been very limited in their extent or scope. Brauer et al. (1970), for example, examined behavioral responses of $A$. planci (stomach eversion versus withdrawal) 
when exposed to extracts of just three different coral species (Acropora formosa, Pocillopora eydouxi, and Porites sp.). Keesing (1990) conducted a much more extensive laboratorybased study, comparing 10 different coral species, but his study was conducted only once in a single large aquarium. The current study comprised a series of six different feeding trials, to assess feeding preferences of $A$. planci for a total of 16 coral species from seven different families.

\section{MATERIALS AND METHODS}

Feeding preferences of $A$. planci were examined during feeding trials conducted in tanks at Lizard Island Research Station $\left(14^{\circ} 40^{\prime} \mathrm{S}\right.$, $145^{\circ} 27^{\prime} \mathrm{E}$ ), on the northern Great Barrier Reef, Australia. A total of 16 coral species from seven different families (Acroporidae: Acropora byacinthus, A. gemmifera, A. nasuta, A. formosa, Montipora undata; Agaricidae: Pavona cactus; Faviidae: Echinopora horrida, Favites abdita, Goniastrea retiformes; Fungiidae: Fungia fungites; Mussidae: Symphyllia recta; Pocilloporidae: Pocillopora damicornis, Stylophora pistillata; Poritidae: Goniopora lobata, Porites cylindrica, Porites lobata) were used in feeding trials. Six to nine individual colonies of each species were collected from the exposed reef crest or from within the lagoon at Lizard Island. Corals were collected a maximum of 48 $\mathrm{hr}$ before being used in feeding trials and were held in flow-through aquariums before use.

In a previous study, crustacean symbionts contained within some coral species (particularly $A$. gemmifera, A. nasuta, $P$. damicornis, and $S$. pistillata) were shown to significantly affect the feeding preferences of $A$. planci (Pratchett 2001). In the study reported here, therefore, coral symbionts were removed from all coral colonies. To remove symbionts, coral colonies were placed in a $1: 10: 100$ solution of clove oil, ethanol, and seawater for 2-3 $\mathrm{min}$. Clove oil is an effective anesthetic for a wide range of invertebrates (e.g., Jones and Morgan 1994), and caused symbionts to rapidly vacate their host colony. Following immersion in clove oil all colonies were carefully inspected with the aid of a small flashlight, and any remaining symbionts (mostly ophiuroids) were removed using plastic forceps. To control for the effects of clove oil on coral colonies, all coral species were subjected to immersion in clove oil irrespective of whether or not they contained crustacean symbionts. Coral colonies were then placed in experimental tanks and left to acclimate for 2-3 hr before the introduction of sea stars. After that time effects of clove oil on the individual coral colonies (polyp retraction and excess mucus production) had passed. Experimental tanks were set up with a single water inlet above and in the center of the tank and a single water outflow to one side. The bottom of the tank was covered with $2 \mathrm{~cm}$ of coarse carbonate sand, which assisted with stabilizing coral colonies placed on the bottom of the tank.

To conduct feeding experiments, uniformsized intact colonies (ca. $800 \mathrm{~cm}^{3}$ ) of each of six different coral species were arranged haphazardly around the edge of the large (420 liter) circular plastic tanks. It was not possible to test preferences simultaneously for all 16 coral species (cf. Keesing 1990). Therefore, a series of six different feeding trials was conducted, each testing different combinations of six different coral species. Selection of coral species for each feeding trial was conducted to provide a diversity of growth forms in each feeding trial. Each combination of coral species was tested in three different tanks using individual sea stars. All sea stars used in feeding trials were collected from back-reef locations (near Corner Beach), where coral communities were fairly depauperate and comprised mostly monospecific stands of $A$. florida and massive Porites species. To standardize for potential differences in the recent feeding history of sea stars, all individuals used in feeding experiments were collected from the reef and then kept in aquariums for 5 days without food before being used in feeding experiments, following Keesing (1990).

At the start of the feeding trials, a single sea star was placed directly in the center of each tank and observations were then made every 1 to $3 \mathrm{hr}$ to record the sequence in which the starfish consumed the various coral 

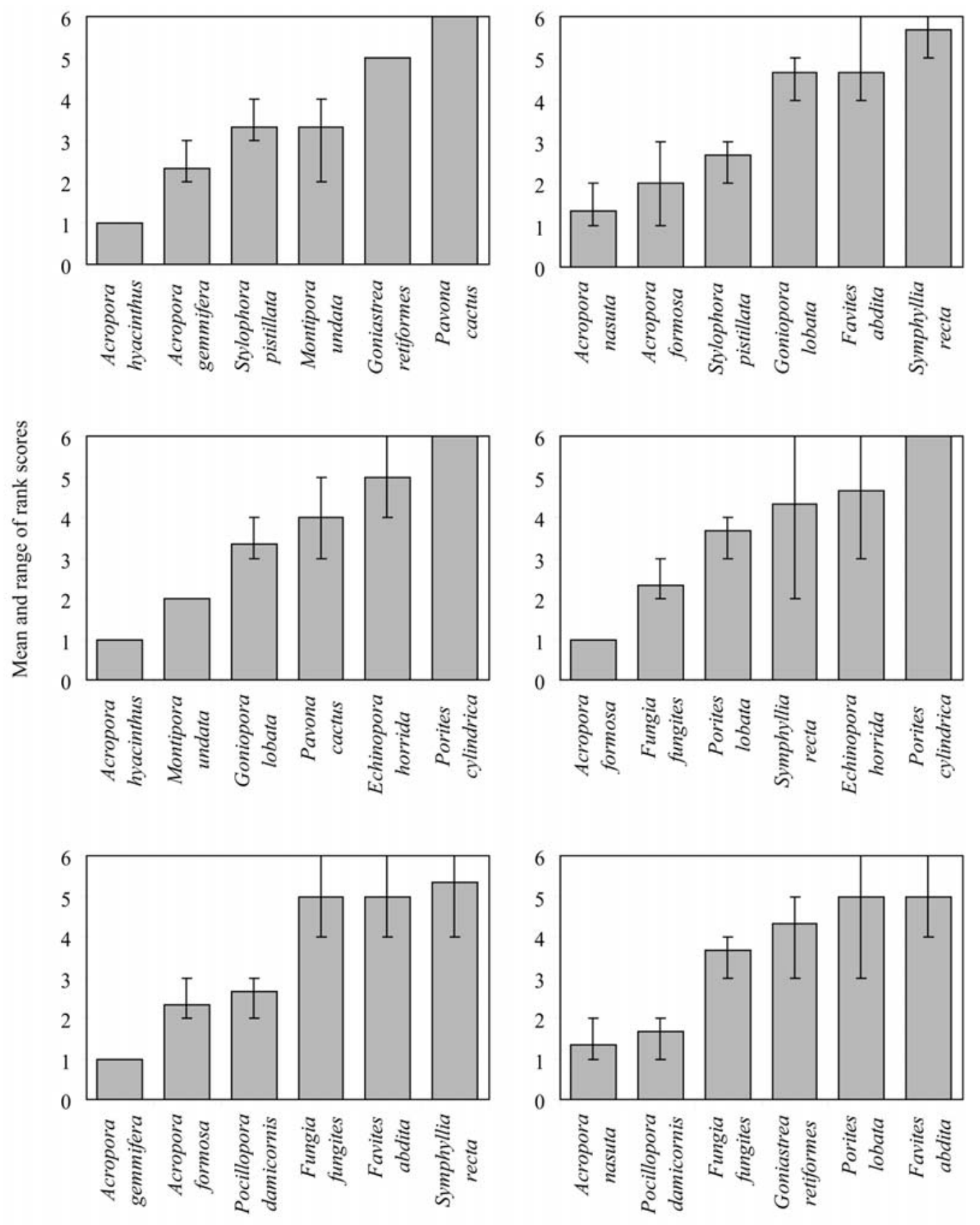

Coral species

FIgUre 1. Mean and range of rank scores for different coral species showing relative feeding preferences of $A$. planci. Ranks were assigned according to the order in which corals were eaten in replicate feeding trials for each combination of coral species $(n=3)$. 
species. Feeding trials were initiated between 1400 and 1600 hours (2-5 hr before sunset) and run for a maximum of 6 days, by which time very few colonies (mostly $<2$ ) remained uneaten. Some trials were terminated after as little as 2 days, as soon as all coral colonies had been consumed. At the end of each feeding trial, all uneaten coral colonies were returned to the reef, the starfish was killed (following specific instructions from the Great Barrier Reef Marine Park Authority), and the tank was thoroughly cleaned before starting a new trial.

Assessment of the feeding preferences of $A$. planci was based on the order in which coral colonies were consumed. Due to the small size of colonies (ca. $800 \mathrm{~cm}^{3}$ ), when sea stars fed on a particular coral they usually consumed the entire colony. On rare occasions (three instances) when sea stars did not consume entire colonies, the coral species was only deemed to have been consumed when more than $50 \%$ of tissue had been removed. Every coral colony within each tank was then assigned a rank from 1 to 6 according to the order in which it was eaten. All colonies that had not been consumed after 6 days were assigned a ranking of 6 , indicating maximum avoidance. Friedman's test was then used to analyze average rank scores of each coral species across replicate feeding trials $(n=3)$, following Zar (1984). These analyses established whether the order in which corals were eaten was statistically nonrandom, indicating that $A$. planci exhibited significant feeding preference across different corals used in each series of feeding trials. Results from the six different sets of feeding trials were then compiled into a single table to ascertain the overall hierarchy of feeding preferences exhibited by $A$. planci for the 16 different coral species studied.

\section{RESULTS}

Crown-of-thorns sea stars exhibited strong and consistent feeding preferences among replicate feeding trials (Figure 1). In the first set of feeding trials, for example, sea stars in all three tanks consumed $A$. byacintbus first and only consumed G. retiformes and P. cactus after all other corals had been consumed. The order in which each of these sea stars consumed A. gemmifera, S. pistillata, and M. undata was slightly different, but the overall order in which corals were consumed was significantly nonrandom (Friedman's test, $\chi_{\mathrm{r}}^{2}=13.86, \mathrm{df}=5, P=0.02$ [Table 1]). Similar patterns were observed in each of the six different feeding trials (Figure 1), with remarkable consistency across replicate sea stars in the order in which they consumed various corals provided (Table 1). This suggests that $A$. planci readily distinguishes between different corals and has marked feeding preferences. Moreover, it appears that feeding preferences of $A$. planci are fairly consistent among individual sea stars.

Overall, there was a well-ordered hierarchy of feeding preferences apparent across the six different feeding trials (Table 1). Acropora byacintbus was the first coral eaten in all six trials in which it was offered. Other readily eaten coral species included $A$. gemmifera, A. nasuta, A. formosa, S. pistillata, M. undata, and P. damicornis (Figure 1). Each of these coral species was eaten by $A$. planci within $24 \mathrm{hr}$ of the start of the experiment, though the order in which they were consumed was sometimes reversed. The next group of corals, comprising G. lobata, F. fungites, G. retiformes, and $P$. cactus, was readily consumed by $A$. planci but only after all species of Acropora, Pocillopora, Montipora, and Stylophora had been eaten (Figure 1). The final group of species (F. abidita, P. lobata, $S$. recta, E. horrida, and P. cylindrica) was only eaten after day 4 and often remained uneaten even after 6 days (Table 1). Of these, P. cylindrica was never eaten in any of the feeding trials in which it was offered and appears to be the least preferred coral prey for A. planci.

In addition to the order in which different coral species were consumed, feeding preferences were apparent from the behavioral responses of sea stars when encountering different coral species. Whenever $A$. planci encountered colonies of $A$. byacinthus it would immediately move on to the colony and begin feeding. In contrast, when sea stars first encountered colonies of E. horrida, S. recta, or P. cylindrica they would retract their tube feet and withdraw away from the colony. How- 
TABLE 1

Feeding Preferences of $A$. planci across Six Different Feeding Trials (F1-F6)

\begin{tabular}{|c|c|c|c|c|c|c|c|}
\hline Coral Species & Growth Form & $\mathrm{F} 1$ & $\mathrm{~F} 2$ & F3 & $\mathrm{F} 4$ & F5 & F6 \\
\hline Acropora byacinthus & Tabular & 1.00 & 1.00 & & & & \\
\hline Acropora gemmifera & Branching & 2.33 & & 1.00 & & & \\
\hline Acropora nasuta & Branching & & & & 1.33 & & 1.33 \\
\hline Acropora formosa & Branching & & & 2.33 & 2.00 & 1.00 & \\
\hline Stylophora pistillata & Branching & 3.33 & & & 2.67 & & \\
\hline Montipora undata & Encrusting & 3.33 & 2.00 & & & & \\
\hline Pocillopora damicornis & Branching & & & 2.67 & & & 1.67 \\
\hline Goniopora lobata & Massive & & 3.33 & & 4.67 & & \\
\hline Fungia fungites & Solitary & & & 5.00 & & 2.33 & 3.67 \\
\hline Goniastrea retiformes & Massive & 5.00 & & & & & 4.33 \\
\hline Pavona cactus & Foliaceous & 6.00 & 4.00 & & & & \\
\hline Favites abdita & Massive & & & $5.00^{*}$ & $4.67^{*}$ & & $5.00^{*}$ \\
\hline Porites lobata & Massive & & & & & 3.67 & $5.00^{*}$ \\
\hline Symphyllia recta & Massive & & & $5.33^{*}$ & $5.67^{*}$ & $4.33^{*}$ & \\
\hline Echinopora horrida & Branching & & $5.00^{*}$ & & & $4.67^{*}$ & \\
\hline Porites cylindrica & Branching & & $6.00^{*}$ & & & $6.00^{*}$ & \\
\hline Friedman's $\chi_{\mathrm{r}}^{2}$ & & 13.86 & 16.81 & 15.86 & 12.90 & 19.66 & 11.38 \\
\hline
\end{tabular}

Note: Average rank scores were assigned for each coral species based on the order in which corals were eaten in three replicate runs of each feeding trial. The significance of feeding preferences was ascertained using Friedman's test, for which the critical value $\left(\chi_{\mathrm{r} 0.05,3,6}^{2}\right)=11.05$.

*, Instances where at least one coral colony remained uneaten at the end of the feeding trial.

ever, behavioral responses of sea stars toward different coral species were equivocal and often changed during the conduct of each feeding trial. When sea stars were first introduced to experimental tanks they tended to avoid all coral species (except $A$. byacintbus) and moved to the vertical sides of the tank, only approaching prey corals after sunset. Even then, sea stars would approach several different coral colonies before they eventually began to feed. On first approach, sea stars would often withdraw from even the most highly preferred coral species, such as A. gemmifera and $P$. damicornis. Also, coral species that were strongly avoided at the start of the experiment (E. horrida, S. recta, and P. lobata) were often eaten toward the end, after sea stars had depleted all other sources of food.

\section{DISCUSSION}

By providing $A$. planci with equal availability of different coral species, this study eliminated many of the factors (e.g., variation in the size, distribution, and abundance of different corals, as well as the potential influence of crustacean symbionts) that have confounded previous estimates of feeding preferences (sensu Moran 1986) and reaffirms that A. planci does have strong feeding preferences for different coral species. Factors that may have influenced the order in which corals were consumed in this study are limited to variation in the nutritional content of corals, the growth form of corals, coral defenses (e.g., mesenterial filaments, nematocysts and/ or secondary metabolites), and/or prior conditioning and learned behavior of the sea stars. The role of nutritional content of prey corals in determining feeding preferences of A. planci, as well as all other corallivores, is poorly understood and requires considerable further investigation. Keesing (1990) explored the relationship between the nutritional value of corals and prey preferences of A. planci, and though the most highly preferred corals (i.e., Acropora spp.) had the highest energy content, other nonpreferred corals also had similarly high energetic content. Keesing (1990) suggested that feeding preferences of A. planci may be more related to morphological and physiological characteristics of corals 
that influence feeding efficiency (e.g., growth form, skeletal structure, and tissue depth) rather than nutritional content per se.

In terms of coral growth form, $A$. planci has been reported to show marked preference for branching and tabular corals over species with massive growth forms (Chesher 1969, Keesing 1990, De'ath and Moran 1998), presumably because they have greater surface complexity, which enables sea stars to feed more efficiently. In the current study, however, there was no consistent pattern between feeding preferences of $A$. planci and growth forms of prey corals (Table 1). Although many branching corals (A. byacinthus, A. gemmifera, A. nasuta, A. formosa, S. pistillata, and $P$. damicornis) were readily eaten by $A$. planci, other branching coral species, such as $E$. horrida and $P$. cylindrica, were among the least preferred corals. The avoidance of these corals may be explained by possession of feeding deterrents (sensu Potts 1981), or A. planci may not be accustomed to feeding on such corals. Ormond et al. (1976) showed that $A$. planci increasingly selects coral species on which it has fed previously. Termed ingestive conditioning, this behavior leads to strongest selection for coral species that are most abundant in the local environment (Ormond et al. 1976). Sea stars used in this study were collected exclusively from back-reef habitats, on the northwestern side of Lizard Island, where they most likely recruited (Pratchett 2005) and probably remained throughout their lives. In contrast, colonies of P. cylindrica and E. horrida were collected from lagoonal habitats on the southern side of the island. It is possible, therefore, that the sea stars had never encountered these corals and thus avoided them. Conversely, the most preferred coral species, A. byacinthus, is also very rare in back-reef habitats (Berumen et al. 2005), so sea stars living exclusively in backreef habitat are unlikely to have encountered this coral. Ingestive conditioning is, therefore, unlikely to account for observed feeding preferences, suggesting that $A$. planci has innate preferences for certain coral species based on some combination of their morphology, physiology, and nutritional composition.
Results from this study substantiate findings from field-based studies conducted on the Great Barrier Reef (Keesing 1990, De'ath and Moran 1998, Pratchett 2001), in Guam (Chesher 1969), southern Japan (Keesing 1992), and the Gulf of Oman (Glynn 1987). Throughout the western Pacific and Indian Ocean, where Acropora corals proliferate, it appears that $A$. planci prefers Acropora and Montipora corals (family Acroporidae) as well as Pocillopora and Stylophora corals (family Pocilloporidae) but tends to avoid corals from the families Faviidae and Poritidae. In the field, $A$. planci feeds predominantly on Acroporidae and Pocilloporidae corals despite the presence of crustacean guards (Glynn 1976, De'ath and Moran 1998), suggesting that preferences for these corals may be moderated by crustacean guards and are actually much stronger than apparent from field studies. Accordingly, this study revealed very strong and consistent preferences for Acroporidae and Pocilloporidae corals without their crustacean guards. Notably, however, sea stars did consume many of the lesspreferred coral species, including $F$. abdita, P. lobata, and E. horrida, following depletion of other more-preferred coral species. This has important implications for the effects of A. planci on coral communities, as discussed by De'ath and Moran (1998). Whereas shortterm and low-density infestations of $A$. planci are likely to lead to localized depletion of only the most highly preferred coral species (i.e., Acroporidae and Pocilloporidae), as was observed by Keesing (1992), extremely severe or chronic outbreaks are likely to cause rapid depletion of highly preferred coral species, followed almost immediately by consumption of many less-preferred coral species, causing extensive devastation across the entire coral community (e.g., Pearson and Endean 1969).

\section{ACKNOWLEDGMENTS}

David Pratchett, Ross Thomas, and Shaun Wilson assisted with experimental procedures. Andrew Baird and Shaun Wilson provided comments that greatly improved the paper. 


\section{Literature Cited}

Berumen, M. L., M. S. Pratchett, and M. I. McCormick. 2005. Within reef variation in the diet and condition of two coral feeding butterflyfish (Pisces: Chaetodontidae). Mar. Ecol. Prog. Ser. 287:217-227.

Birkeland, C., and J. S. Lucas. 1990. Acanthaster planci: Major management problem of coral reefs. CRC Press, Boca Raton, Florida.

Branham, J. M., S. A. Reed, and J. H. Bailey. 1971. Coral-eating sea stars Acanthaster planci in Hawaii. Science (Washington, D.C.) 172:1155-1157.

Brauer, R. W., M. R. Jordan, and D. J. Barnes. 1970. Triggering of the stomach eversion reflex of Acanthaster planci by coral extracts. Nature (Lond.) 228:344346.

Chesher, R. H. 1969. Destruction of Pacific corals by the sea star Acanthaster planci. Science (Washington, D.C.) 18:280-283.

Chess, J. R., E. S. Hobson, and D. F. Howard. 1997. Interactions between Acanthaster planci (Echinodermata, Asteroidea) and scleractinian corals at Kona, Hawai'i. Pac. Sci. 51:121-133.

Dana, T. F., W. A. Newman, and E. W. Fager. 1972. Acanthaster aggregations: Interpreted as primarily responses to natural phenomena. Pac. Sci. 26:355-372.

De'ath, G., and P. J. Moran. 1998. Factors affecting the behaviour of crown-of-thorns starfish (Acanthaster planci L.) on the Great Barrier Reef: 2: Feeding preferences. J. Exp. Mar. Biol. Ecol. 220:107-126.

Glynn, P. W. 1973. Acanthaster: Effect on coral reef growth in Panama. Science (Washington, D.C.) 180:504-506.

- 1974. The impact of Acanthaster on corals and coral reefs in the eastern Pacific. Environ. Conserv. 1:295-303.

- 1976. Some physical and biological determinants of coral community structure in the eastern Pacific. Ecol. Monogr. 46:431-456.

. 1987. Some ecological consequences of coral-crustacean guard mutualisms in the Indian and Pacific Oceans. Symbiosis 4:301-324.

Hughes, R. N. 1980. Optimal foraging theory in the marine context. Oceanogr. Mar. Biol. Annu. Rev. 18:423-481.

Jones, D. S., and G. J. Morgan. 1994. A field guide to crustaceans of Australian waters. Reed, Chatswood.

Keesing, J. K. 1990. Feeding biology of the Crown-of-Thorns starfish, Acanthaster planci (Linnaeus). Ph.D. diss., James Cook University of North Queensland, Townsville, Australia.

- 1992. Influence of persistent subinfestation density Acanthaster planci (L.) and high density Echinometra mathaei (de Blainville) populations on coral reef community structure in Okinawa, Japan. Proc. 7th Int. Coral Reef Symp. 2:769-779.

Moran, P. J. 1986. The Acanthaster phenomenon. Oceanogr. Mar. Biol. Annu. Rev. 24:379-480.

Ormond, R. F. G., N. J. Hanscomb, and D. H. Beach. 1976. Food selection and learning in the crown-of-thorns starfish Acanthaster planci (L.). Mar. Behav. Physiol. 4:93-105.

Pearson, R. G., and R. Endean. 1969. A preliminary study of the coral predator Acanthaster planci (L.) (Asteroidea) on the Great Barrier Reef. Fish. Notes 3:27-55.

Porter, J. W. 1972. Predation by Acanthaster planci and its effect on coral species diversity. Am. Nat. 106:487-492.

Potts, D. C. 1981. Crown-of-thorns starfish -man-induced pest or natural phenomenon? Pages 54-86 in R. E. Kitching and R. E. Jones, eds. The ecology of pests: Some Australian case histories. CSIRO Press, Melbourne.

Pratchett, M. S. 2001. Influence of coral symbionts on feeding preferences of crown-of-thorns starfish Acanthaster planci in the western Pacific. Mar. Ecol. Prog. Ser. 214:111-119.

- 2005. Dynamics of an outbreak population of Acanthaster planci at Lizard Island, northern Great Barrier Reef (19951999). Coral Reefs 24:453-462.

Sonoda, K., and V. J. Paul. 1993. Effect of stony coral extracts on feeding by Acanthaster planci. Mar. Ecol. Prog. Ser. 102:161-168.

Zar, J. H. 1984. Biostatistical analysis. Prentice-Hall, Englewood Cliffs, New Jersey. 